\title{
Composição, abundância e distribuição espacial do zooplâncton no complexo estuarino de Paranaguá durante o inverno de 1993 e o verão de 1994
}

\section{(Zooplankton composition, abundance and spatial distribution in the estuarine complex of Paranaguá during winter 1993 and summer 1994)}

\author{
Rubens M. Lopes*; Rosinei do Vale \& Frederico P. Brandini \\ Universidade Federal do Paraná \\ Centro de Estudos do Mar \& Curso de Pós-Graduação em Zoologia \\ (Av. Beira Mar s $/ \mathrm{n}^{\circ}, 83255-000$, Pontal do Paraná, PR, Brasil) \\ *e-mail: rmlopes@cem.ufpr.br
}

- Abstract: Zooplankton community structure was investigated in the estuarine complex of Paranaguá (Southern Brazil) during July.1993 (winter) and February-March 1994 (summer). Copepods belonging to the genera Acartia, Paracalanus, Parvocalamus, Pseudodiaptomus, Temora, Oithona and Euterpina dominated the zooplankton associations, attaining up to $90 \%$ of total densities. Pseudodiaptomus richardi was the dominant estuarine copepod in oligohaline stretches with salinities below 15. Estuarine marine species such as Acartia tonsa, Oithona hebes and Oithona oswaldocruzi reached high densities in salinities ranging from 17 to 25 . Other abundant estuarine marine species including Acartia lilljeborgi and Pseudodiaptomus acutus occurred in a broader salinity range. Marine euryhaline copepods were found in salinities as low as 15 , but were usually more abundant in areas under the influence of coastal waters. Several marine stenohaline species associated with the warm waters of the Brazil Current were recorded in the euhaline areas. Other important zooplanktonic groups in this estuarine complex were tintinnids, appendicularians, cladocerans and meroplanktonic larvae of polychaetes and decapods. Density maxima (up to $82400 \mathrm{org} . \mathrm{m}^{-3}$ ) were found in the intermediate stretches - in salinities varying from 15 to 30 - corresponding approximately to the distributional pattern of phytoplankton biomass.

- Resumo: A estrutura das associações zooplanctônicas do complexo estuarino de Paranaguá foi estudada no inverno de 1993 e no verão de 1994. Copépodes dos gêneros Acartia, Paracalanus, Parvocalanus, Temora, Pseudodiaptomus, Oithona e Euterpina foram dominantes, atingindo até cerca de $90 \%$ da densidade total. A única espécie que ocorreu preferencialmente em salinidades inferiores a 15 foi o calanóide $P$ seudodiaptomus richardi, que representa o principal componente do holoplâncton nos setores oligohalinos. Acartia tonsa e Oithona oswaldocruzi predominaram nos trechos intermediários, associadas a outras espécies estuarino-marinhas que suportam maiores variações de salinidade, como Acartia lilljeborgi, Pseudodiaptomus acutus e Oithona hebes. Espécies marinho-eurihalinas como Temora turbinata, Paracalanus quasimodo, Oithona simplex e Euterpina acutifrons ocorreram em salinidades tão baixas quanto 15, mas foram mais abundantes na área externa influenciada pela água costeira. Várias espécies marinho-estenohalinas, associadas principalmente às águas quentes da Corrente do Brasil, foram registradas no setor euhalino. Outros grupos zooplanctônicos numericamente importantes foram os tintiníneos, apendiculárias, cladóceros e alguns representantes do meroplâncton, como as larvas de poliquetas e decápodes. Os máximos de abundância do zooplâncton (até cerca de 82000 org. $\mathrm{m}^{-3}$ ) ocorreram nos setores intermediários, em salinidades variando entre 15 e 30, coincidindo aproximadamente com $o$ padrão de distribuição da biomassa fitoplanctônica.

- Descriptors: Zooplankton, Copepoda, Estuaries, Composition, Abundance, Spatial distribution, Southern Brazil.

- Descritores: Zooplâncton, Copepoda, Estuários, Composição, Abundância, Distribuição espacial, Região Sul do Brasil. 


\section{Introdução}

As associações zooplanctônicas têm um papel central nos ecossistemas estuarinos. $\mathrm{O}$ plâncton herbívoro consome proporções variáveis da produção primária fitoplanctônica, podendo controlar 0 crescimento das populações algais durante certos períodos do ano (Heinle, 1966; Carlson, 1978; Nicolajsen et al., 1983; Dam \& Peterson, 1993). A atividade alimentar destes animais tem também conseqüências importantes para a ciclagem de nutrientes inorgânicos em águas salobras, através da excreção de diversas formas de nitrogênio e fósforo (Smith, 1978). Além disto, os organismos zooplanctônicos constituem os principais itens da dieta de muitos carnívoros estuarinos, incluindo uma série de espécies de peixes de interesse econômico (Turner, 1984).

Informações sobre a composição específica, a abundância e a distribuição espaço-temporal do zooplâncton estão disponiveis para vários ambientes estuarinos da costa brasileira, com destaque para a área de Suape-Itamaracá (Neumann-Leitão, 1994), o complexo estuarino-lagunar de Cananéia-Iguape (Almeida Prado, 1972; Tundisi, 1972; Tundisi et al., 1973, 1978), a estação ecológica da Juréia (LansacTôha, 1985; Lopes et al., 1986; Lopes, 1994) e a Lagoa dos Patos (Montú, 1980; Duarte, 1986; Rocha, 1994).

O zooplâncton do complexo estuarino de Paranaguá é ainda pouco conhecido, embora este complexo represente um dos principais ecossistemas costeiros da região sul-sudeste do Brasil. Os únicos estudos sobre a distribuição espaço-temporal do mesozooplâncton e do ictioplâncton foram realizados no trecho compreendido entre a llha do Mel e a parte central da baía de Paranaguá propriamente dita, além de poucas estações visitadas na Baía das Laranjeiras (Sinque et al., 1982, 1983; Montú \& Cordeiro, 1988; Sinque, 1989; Almeida \& Spach, 1992). Recentemente, Godefroid (1997) analisou a variação temporal do ictioplâncton na zona de arrebentação da praia de Pontal do Sul, localizada junto ao Canal da Galheta, principal acesso à baía. Montú \& Cordeiro (op. cit.) obtiveram um conjunto significativo de dados sobre o mesozooplâncton da baía ao longo de um ciclo anual, mas com uma abrangência espacial relativamente restrita. Não há informações sobre o zooplâncton dos setores oligohalinos deste complexo estuarino.

O objetivo deste trabalho é determinar a composição, a abundância e a distribuição espacial do zooplâncton nos diferentes setores do complexo estuarino de Paranaguá, no inverno e no verão, em relação a alguns parâmetros ambientais básicos.

\section{Material e métodos}

\section{Amostragem}

As coletas do zooplâncton foram feitas durante o inverno de 1993 (19 a 23 de julho) e o verão de 1994 (9 de fevereiro a 24 de março) em 22 estações, distribuídas conforme se segue (Fig. 1):

Setor BPA - estações 1 a 6 , dispostas ao longo do eixo leste-oeste do complexo estuarino, que inclui a Baía de Paranaguá e a Baía de Antonina;

Setor LGB - estações 7 a 15 , dispostas ao longo do eixo norte-sul, que inclui a Baía das Laranjeiras, a Baía de Guaraqueçaba e a Enseada do Benito;

Setor SBP - estações 16 a 19, entre a barra do Superagüi e a Baía dos Pinheiros;

Setor RIO - estações 20 a 22, localizadas nos rios Itiberê (est. 21) e Guaraguaçu (est. 20 e 22).

Em cada estação foram obtidas amostras de água na superficie (aproximadamente $0,5 \mathrm{~m}$ de profundidade) com uma garrafa Van Dorn, para a determinação da concentração de clorofila- $a$, da temperatura (termômetro de mercúrio-padrão) e da salinidade (termosalinômetro Kalhsico RS5.3 ou refratômetro). Neste trabalho é utilizada a escala de salinidade prática, segundo as recomendações da UNESCO (1985). A análise da clorofila- $a$ foi feita através do método espectrofotométrico descrito por Parsons et al. (1984). A transparência da água foi determinada com um disco de Secchi. Em geral, as coletas foram realizadas durante a maré enchente ou cheia.

As amostras de zooplâncton foram coletadas através de dois procedimentos distintos: 1) arrastos horizontais subsuperficiais com uma rede cônica de $37 \mathrm{~cm}$ de diâmetro de boca e $300 \mu \mathrm{m}$ de abertura de malha, equipada com fluxốmetro Hydrobios. $\mathrm{O}$ tempo de arrasto variou entre 3 e 5 minutos e o volume de água filtrado pela rede foi de 800 a 1600 litros; 2) bombeamento da água superficial através de uma rede com malha de $63 \mu \mathrm{m}$, utilizando uma motobomba Stihl modelo P-850. A vazão da bomba foi determinada no início de cada estação, medindo-se o tempo necessário para encher um balde graduado de 20 litros de capacidade. O volume de água filtrado para cada amostra variou entre 200 e 700 litros.

Tanto no caso dos arrastos horizontais como nas amostragens com bomba, os organismos foram fixados em solução de formaldeído tamponado, com concentração final de $4 \%$.

Comparações entre as coletas com rede e bomba mostraram que a maioria dos táxons e estágios de desenvolvimento do zooplâncton foram capturados seletivamente de acordo com o método utilizado (dados não apresentados). Os resultados 


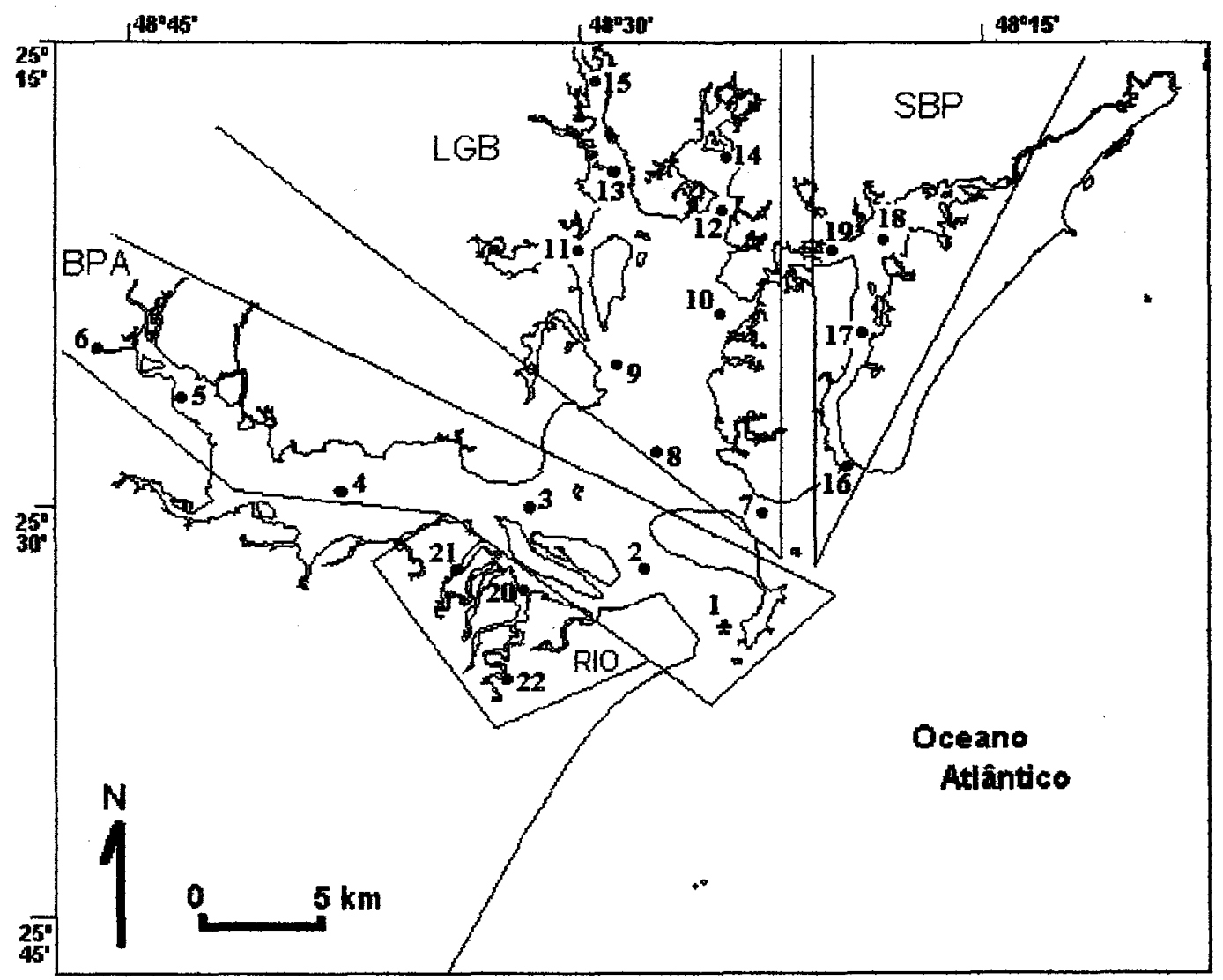

Fig. 1. Mapa do complexo estuarino de Paranaguá, mostrando o posicionamento das estações de coleta nos diferentes setores - Baía de Paranaguá e Baía de Antonina (BPA); Baía das Laranjeiras, Baía de Guaraqueçaba e Enseada do Benito (LGB); Canal do Superagüi e Baía dos Pinheiros (SBP); rios Guaraguaçu e ltiberê (RIO).

descritos a seguir levam em conta os valores de abundância mais elevados de cada par amostral (redes de 300 ou $63 \mu \mathrm{m}$ ), tomados em conjunto para todas as estações. Nos casos em que não houve diferença significativa entre os dois tipos de amostradores, foram utilizados os valores de abundância obtidos a partir da rede de $300 \mu \mathrm{m}$.

Os dados das amostras de bomba $(>63 \mu \mathrm{m})$ foram utilizados para todos os estágios de desenvolvimento dos copépodes ciclopóides, harpacticóides e para o calanóide Parvocalanus crassirostris, assim como para as larvas de decápodes. No caso dos demais copépodes calanóides foram utilizados os dados das amostras coletadas através dos arrastos $(>300 \mu \mathrm{m})$ para os copepoditos IV-VI e das amostras de bomba ( $>63 \mu \mathrm{m})$ para os copepoditos I-III e náuplios. Os valores de abundância empregados para os táxons remanescentes foram os obtidos a partir dos arrastos com a rede de $300 \mu \mathrm{m}$.

$\mathrm{Na}$ maioria dos casos, a identificação e a contagem dos organismos foram realizadas em alíquotas das amostras totais, obtidas através de um subamostrador tipo Motoda, ou com pipeta Stempel de $5 \mathrm{ml}$ (Omori \& Ikeda, 1984). Um número mínimo de 30 indivíduos de cada táxon dominante foi contado por amostra, perfazendo sempre mais de 200 indivíduos analisados em cada subamostra, de acordo com as recomendações de Frontier (1981). As amostras totais foram também analisadas qualitativamente para o registro de táxons pouco abundantes, eventualmente não incluídos nas subamostras. Sempre que possivel, a identificação do zooplâncton foi feita até a categoria de espécie, principalmente para os grupos taxonômicos dominantes. Os náuplios, copepoditos juvenis e copepoditos adultos foram discriminados por espécie nas contagens. Porém, para efeito de simplificação na apresentação dos dados, os valores de abundância destes estágios de desenvolvimento foram somados para a obtenção da abundância total de cada espécie.

A abundância do zooplâncton (org. $\mathrm{m}^{-3}$ ) foi calculada dividindo-se $o$ número de indivíduos presentes na amostra total pelo volume de água filtrado. A contribuição dos diferentes táxons para a abundância total do zooplâncton foi expressa pela abundância relativa (\%) de cada táxơn na amostra total. 


\section{Resultados}

\section{Hidrografia}

A variação espacial dos parâmetros hidrográficos no inverno e no verão é apresentada na Tabela 1 . A temperatura da água variou entre 19 e $21^{\circ} \mathrm{C}$ durante o inverno e entre 26 e $30,5^{\circ} \mathrm{C}$ durante o verão. $\mathrm{Em}$ todos os setores amostrados, a salinidade decresceu em direção às estações internas, variando entre 7 e 34 no inverno e entre 0,3 e 31 no verão. A transparência da água variou entre 0,5 e 2,2 metros no periodo de inverno e entre 0,7 e 3,4 metros no verão. A clorofila$a$ variou entre 0,2 e $6,7 \mu \mathrm{g} . \mathrm{I}^{-1}$ durante o inverno e entre 0,3 e $6,2 \mu \mathrm{g} . \mathrm{l}^{-1}$ no verão, com maiores concentrações nas áreas intermediárias (meso- e polihalinas).

Tabela 1. Dados hidrográficos obtidos nas coletas de julho/1993 (inverno) e fevereiro-março/1994 (verão) nas diferentes estações e setores do complexo estuarino de Paranaguá $O$ posicionamento das estações e as siglas dos setores estão indicados na Figura 1.

\begin{tabular}{|c|c|c|c|c|c|}
\hline $\begin{array}{c}\text { Setor/ } \\
\text { Estação }\end{array}$ & Periodo do ano & $\begin{array}{c}\text { Temperatura } \\
\left({ }^{\circ} \mathrm{C}\right)\end{array}$ & Salinidade & $\begin{array}{l}\text { Transparência } \\
\text { (metros) }\end{array}$ & $\begin{array}{c}\text { Clorofila-a } \\
\left(\mu \mathrm{g} . \mathrm{I}^{-1}\right)\end{array}$ \\
\hline BPA - 1 & Inverno & 20,0 & $\overline{34,0}$ & 2,00 & 0,92 \\
\hline BPA - 2 & & 20,0 & 31,0 & 1,40 & 2,67 \\
\hline BPA - 3 & & 20,0 & 28,0 & 1,70 & 0,21 \\
\hline $\mathrm{BPA}-4$ & & 20,5 & 27,0 & 1,30 & 2,14 \\
\hline BPA - 5 & & 21,0 & 21,0 & 1,20 & 1,98 \\
\hline BPA - 6 & & 19,0 & 12,0 & 0,90 & 2,77 \\
\hline LGB - 7 & & 20,0 & 31,0 & 0,50 & 1,28 \\
\hline LGB - 8 & & 20,0 & 30,0 & 1,40 & 0,91 \\
\hline LGB - 9 & & 20,5 & 26,5 & 2,20 & 1,28 \\
\hline LGB - 10 & & 20,0 & 25,5 & 1,10 & 3,10 \\
\hline LGB - 11 & & 21,0 & 24,5 & 2,00 & 4,27 \\
\hline LGB - 12 & & 21,0 & 20,0 & 0,80 & 2,85 \\
\hline LGB - 13 & & 20,0 & 17,5 & 0,80 & 3,95 \\
\hline LGB - 14 & & 21,0 & 17,0 & 0,80 & 1,73 \\
\hline LGB - 15 & & 20,5 & 7,0 & 1,20 & 5,34 \\
\hline SBP - 16 & & 20,0 & 33,0 & 1,80 & 1,07 \\
\hline SBP -17 & & 20,0 & 30,0 & 1,70 & 3,20 \\
\hline SBP - 18 & & 22,0 & 26,0 & 2,70 & 0,85 \\
\hline SBP - 19 & & 22,0 & 25,0 & 1,50 & 3,77 \\
\hline RIO - 20 & & 22,0 & 30,0 & 1,80 & 1,42 \\
\hline RIO - 21 & & 21,0 & 20,5 & 1,00 & 6,68 \\
\hline RIO - 22 & & 20,5 & 9,5 & 0,80 & 3,05 \\
\hline BPA - 1 & Verão & 30,0 & 31,0 & 2,00 & 0,85 \\
\hline BPA - 2 & & 26,0 & 22,0 & 1,20 & 1,60 \\
\hline BPA - 3 & & 27,0 & 18,0 & 1,20 & 0,43 \\
\hline BPA - 4 & & 29,0 & 11,5 & 1,10 & 0,32 \\
\hline BPA - 5 & & 28,0 & 10,5 & 0,90 & 4,15 \\
\hline BPA - 6 & & 26,0 & 0,0 & 0,80 & 4,37 \\
\hline LGB -7 & & 29,5 & 22,0 & 1,00 & 3,23 \\
\hline LGB - 8 & & 29,0 & 24,0 & 1,40 & 3,54 \\
\hline LGB - 9 & & 30,5 & 22,0 & 1,00 & 2,27 \\
\hline LGB - 10 & & 28,0 & 21,0 & 0,90 & 3,41 \\
\hline LGB - 11 & & 28,0 & 18,0 & 2,20 & 4,21 \\
\hline LGB - 12 & & 28,8 & 17,5 & 1,40 & 3,38 \\
\hline LGB - 13 & & 28,7 & 21,0 & 1,60 & 5,17 \\
\hline LGB - 14 & & 28,2 & 11,0 & 0,80 & 6,22 \\
\hline LGB - 15 & & 27,2 & 7,5 & 1,60 & 1,65 \\
\hline SBP - 16 & & 29,0 & 30,0 & 3,40 & 5,15 \\
\hline SBP -17 & & 29,0 & 25,0 & 2,40 & 1,60 \\
\hline SBP - 18 & & 29,1 & 23,0 & 2,00 & 0,73 \\
\hline SBP - 19 & & 28,0 & 21,0 & 0,80 & 5,40 \\
\hline RIO - 20 & & 26,5 & 20,5 & 1,10 & 2,67 \\
\hline RIO - 21 & & 27,5 & 19,0 & 1,10 & 0,85 \\
\hline RIO - 22 & & 27,0 & 3,5 & 0,70 & 1,50 \\
\hline
\end{tabular}


Cerca de $75 \%$ dos valores de clorofila acima de $3,0 \mu \mathrm{g} . \mathrm{I}^{-1}$ ocorreram em salinidades entre $10 \mathrm{e} 26$, sem correlação linear significativa $(p>0,05)$ destes dois parâmetros (Fig. 2). A transparência da água foi correlacionada positivamente com a salinidade $(\mathrm{r}=0,503 ; \mathrm{p}<0,01)$, porém os valores de transparência estiveram em geral restritos entre 0,8 e 2,0 metros (Fig. 3).

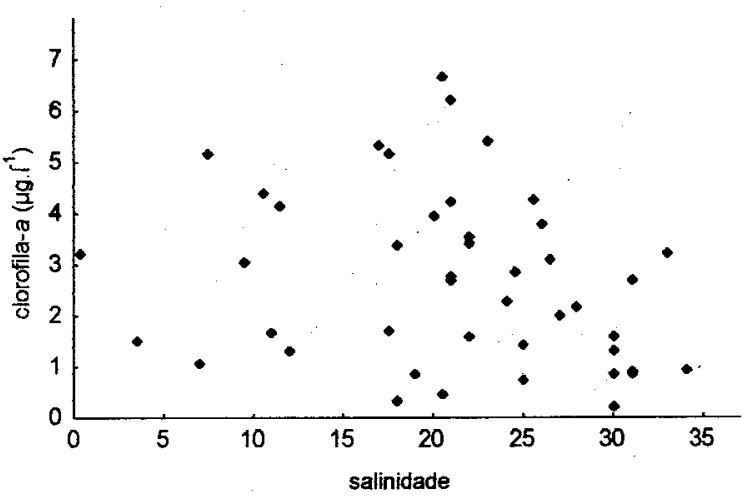

Fig. 2. Concentração de clorofila- $a$ em relação ao gradiente de salinidade. Valores referentes a julho de 1993 (inverno) e fevereiro-março de 1994 (verão).

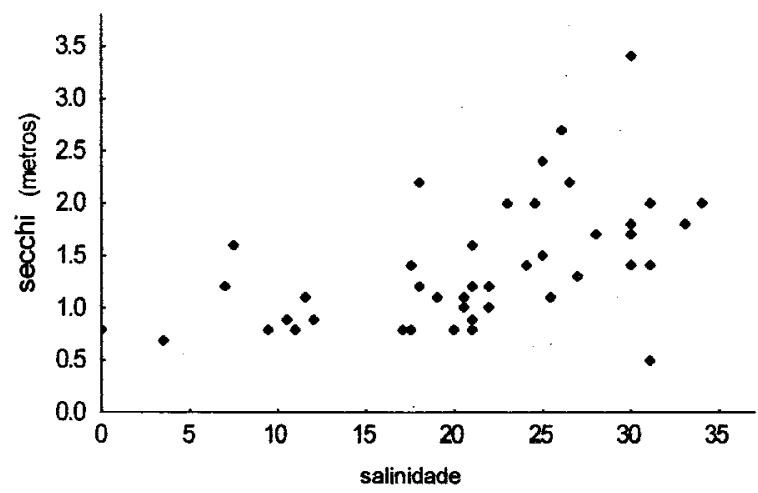

Fig. 3. Transparência da água, medida pelo disco de Secchi, em relação ao gradiente de salinidade. Valores referentes a julho de 1993 (inverno) e fevereiromarço de 1994 (verão).

\section{Zooplâncton}

\section{Composição qualitativa}

Copepoda foi o grupo que apresentou o maior número de táxons identificados, com um total de 26 espécies. As espécies mais freqüentes, presentes em mais de $50 \%$ das amostras, foram Acartia lilljeborgi, A. tonsa, Paracalanus quasimodo, Parvocalanus crassirostris, Pseudodiaptomus acutus, T. turbinata, Oithona hebes, $O$. oswaldocruzi e Euterpina acutifrons. Pseudodiaptomus richardi, Labidocera fluviatilis, Oithona simplex e Longipedia sp. ocorreram entre 25 e $50 \%$ das amostras, enquanto que as demais espécies de copépodes tiveram uma freqüência menor que $25 \%$.

Comparativamente poucas espécies de outros táxons holoplanctônicos foram encontradas, destacando-se os cladóceros, quetognatos e apendiculárias, representados por três espécies cada. As espécies mais freqüentes destes grupos foram Penilia avirostris (Cladocera), Sagitta friderici (Chaetognatha) e Oikopleura dioica (Appendicularia), presentes respectivamente em 36, 55 e $86 \%$ das amostras. Também foi encontrada uma espécie de cladócero bêntico do gênero Chydorus. Duas espécies de taliáceos foram registradas (Thalia democratica e Doliolum nationalis), porém em baixas freqüências. As únicas espécies coletadas de Siphonophora (Muggiaea kochi) e Ostracoda (Euconchoecia chierchiae) também ocorreram em poucas amostras. Entre as hidromedusas, a espécie dominante foi Liriope tetraphylla. Os principais grupos do meroplâncton foram os moluscos (gastrópodes e bivalves), poliquetas, cirripédios e decápodes. As larvas de briozoários, equinodermes e foronídeos ocorreram em menores abundâncias e freqüências, assim como os ovos e larvas de peixes.

Além dos táxons citados, foram registrados alguns organismos ticoplanctônicos como nemátodes, ácaros aquáticos (Hydracarina), isópodes parasitas (epicarídeos), anfípodes e tanaidáceos. Uma lista completa dos táxons registrados encontra-se na Tabela 2.

\section{Abundância relativa}

O zooplâncton total foi dominado pelos copépodes que, além de apresentarem o maior número de espécies, tiveram as maiores abundâncias relativas. Os copépodes representaram, em média, cerca de 83 a $89 \%$ dos organismos amostrados no inverno e entre 75 e $79 \%$ no verão, exceto no setor RIO, onde a abundância relativa do grupo atingiu $\mathbf{8 8 , 5 \%}$ (Tab. 3). Os tintiníneos e as apendiculárias foram subdominantes na maioria das estações em que foram registrados, com abundâncias relativas variando de 1 a $12 \%$ e 2 a $8 \%$, respectivamente. Os cladóceros e quetognatos não contribuíram de forma significativa para a abundância total do zooplâncton na maior parte das estações, constituindo em geral menos de $1 \%$ do zooplâncton total nos diferentes setores do complexo estuarino. $\mathrm{O}$ mesmo foi observado em relação aos grupos do meroplâncton. No entanto, estes organismos foram importantes em algumas estações, conforme relatado adiante. 
Tabela 2. Lista dos táxons zooplanctônicos identificados no complexo estuarino de Paranaguá durante as coletas de julho/1993 (inverno) e fevereiro-março/1994 (verão). A nomenclatura das espécies está baseada em Boltovskoy (1981), Rocha (1986) e Mauchline (1998).

\begin{tabular}{|c|c|}
\hline Tintinnina & Copepoda (cont.) \\
\hline Hydromedusae & Cyclopoida \\
\hline Liriope tetraphylla (Chamisso \& Eysenhardt, 1821) & Halicyclops spp. \\
\hline Siphonophora & Oithona hebes Giesbrecht, 1891 \\
\hline Muggiaea kochi (Wild, 1844) & Oithona oswaldocruzi Oliveira, 1945 \\
\hline Rotifera & Oithona simplex Farran, 1913 \\
\hline Turbellaria & Poecilostomatoida \\
\hline Nematoda & Corycaeus amazonicus F. Dahl, 1894 \\
\hline Gastropoda (larvas) & Corycaeus giesbrechti $\mathrm{F}$. Dahl, 1894 \\
\hline Bivalvia & Farranula gracilis (Dana, 1853) \\
\hline Polychaeta (larvas) & Oncaea media Giesbrecht, 1891 \\
\hline Cladocera & Oncaea venusta Philippi, 1843 \\
\hline Penilia avirostris Dana, 1849 & Harpacticoida \\
\hline Evadne tergestina (Claus, 1862) & Euterpina acutifrons (Dana, 1852) \\
\hline Pleopis schmakeri (Poppe, 1889) & Clytemnestra scutellata Dana, 1848 \\
\hline Isopoda (Epicaridea) & Longipedia sp. \\
\hline Ostracoda & Cirripedia (larvas) \\
\hline Euconchoecia chierchiae Müller, 1891 & Decapoda (larvas) \\
\hline Copepoda & Amphipoda \\
\hline Calanoida & Tanaidacea \\
\hline Acartia lilljeborgi Giesbrecht, 1889 & Bryozoa (larvas) \\
\hline Acartia tonsa Dana, 1849 & Echinodermata \\
\hline Calocalanus styliremis Giesbrecht, 1888 & Chaetognatha \\
\hline Calanopia americana F. Dahl, 1894 & Sagitta enflata Grassi, 1889 \\
\hline Centropages velificatus (Oliveira, 1946) & Sagitta friderici Ritter-Zahoni, 1911 \\
\hline Clausocalanus furcatus (Brady, 1883) & Sagitta tenuis Conant, 1896 \\
\hline Eucalanus pileatus Giesbrecht, 1888 & Appendicularia \\
\hline Labidocera fluviatilis F. Dahl, 1894 & Oikopleura dioica Fol, 1872 \\
\hline Paracalanus aculeatus Giesbrecht, 1888 & Oikopleura longicauda (Vogt, 1854) \\
\hline Paracalanus quasimodo Bowman, 1971 & Fritillaria sp. \\
\hline Parvocalanus crassirostris (F. Dahl, 1894) & Phoronidae (larvas) \\
\hline Pontellopsis brevis (Giesbrecht, 1889) & Thaliacea \\
\hline Pseudodiaptomus acutus (F. Dahl, 1894) & Thalia democratica (Forskål, 1775) \\
\hline Pseudodiaptomus richardi (F. Dahl, 1894) & Piscis (ovos e larvas) \\
\hline \multicolumn{2}{|l|}{ Temora turbinata (Dana, 1849) } \\
\hline Temora stylifera (Dana, 1849) & \\
\hline
\end{tabular}


Tabela 3. Abundância relativa média (\%) dos principais grupos do zooplâncton coletados nos quatro setores do complexo estuarino de Paranaguá no inverno de 1993 e verão de 1994. Os desvios-padrão das médias estão indicados entre parênteses. Siglas dos setores: vide Figura 1.

\begin{tabular}{|c|c|c|c|c|c|c|c|c|}
\hline \multirow[b]{2}{*}{ Táxons/Setores } & \multicolumn{4}{|c|}{$\begin{array}{c}\text { Inverno } \\
(\%)\end{array}$} & \multirow[b]{2}{*}{ BPA } & \multirow[b]{2}{*}{ LGB } & \multicolumn{2}{|c|}{$\begin{array}{c}\text { Verão } \\
(\%)\end{array}$} \\
\hline & $\boldsymbol{B P A}$ & LGB & SBP & RIO & & & SBP & RIO \\
\hline Tintinnina & $\begin{array}{c}\mathbf{3 , 1} \\
(3,3)\end{array}$ & $\begin{array}{c}1,2 \\
(1,9)\end{array}$ & $\begin{array}{c}\mathbf{3 , 8} \\
(5,1)\end{array}$ & $\begin{array}{c}\mathbf{3 , 3} \\
(4,7)\end{array}$ & $\begin{array}{c}5,4 \\
(4,4)\end{array}$ & $\begin{array}{c}5,0 \\
(5,9)\end{array}$ & $\begin{array}{l}12,2 \\
(6,2)\end{array}$ & $\begin{array}{r}0,6 \\
(0,8)\end{array}$ \\
\hline Mollusca (larvas) & $\begin{array}{c}\mathbf{0 , 8} \\
(1,1)\end{array}$ & $\begin{array}{c}2,3 \\
(3,5)\end{array}$ & $\begin{array}{c}\mathbf{0 , 9} \\
(0,7)\end{array}$ & $\begin{array}{c}1,6 \\
(1,2)\end{array}$ & $\begin{array}{c}2,7 \\
(2,3)\end{array}$ & $\begin{array}{c}3,3 \\
(2,1)\end{array}$ & $\begin{array}{c}\mathbf{0 , 7} \\
(0,6)\end{array}$ & $\begin{array}{c}2,0 \\
(2,9)\end{array}$ \\
\hline Polychaeta (larvas) & $\begin{array}{c}2,3 \\
(1,7)\end{array}$ & $\begin{array}{c}\mathbf{0 , 2} \\
(0,2)\end{array}$ & $\begin{array}{c}1,1 \\
(1,0)\end{array}$ & $\begin{array}{c}\mathbf{0 , 1} \\
(0,1)\end{array}$ & $\begin{array}{c}1,1 \\
(1,8)\end{array}$ & $\begin{array}{c}1,1 \\
(1,2)\end{array}$ & $\begin{array}{c}\mathbf{0 , 3} \\
(0,2)\end{array}$ & $\begin{array}{c}1,4 \\
(2,0)\end{array}$ \\
\hline Copepoda & $\begin{array}{l}\mathbf{8 8 , 9} \\
(4,2)\end{array}$ & $\begin{array}{c}84,1 \\
(12,2)\end{array}$ & $\begin{array}{c}\mathbf{8 3 , 2} \\
(14,0)\end{array}$ & $\begin{array}{l}\mathbf{8 8 , 9} \\
(6,0)\end{array}$ & $\begin{array}{l}79,2 \\
(6,7)\end{array}$ & $\begin{array}{c}76,8 \\
(10,2)\end{array}$ & $\begin{array}{c}75,0 \\
(10,0)\end{array}$ & $\begin{array}{l}\mathbf{8 8 , 5} \\
(7,2)\end{array}$ \\
\hline Cladocera & $\begin{array}{c}0,6 \\
(1,0)\end{array}$ & ausente & $\begin{array}{c}4,2 \\
(8,3)\end{array}$ & ausente & $\begin{array}{c}1,1 \\
(1,6)\end{array}$ & $\begin{array}{c}0,5 \\
(0,9)\end{array}$ & $\begin{array}{c}0,7 \\
(1,2)\end{array}$ & $\begin{array}{c}0,7 \\
(1,0)\end{array}$ \\
\hline Cirripedia (náuplios) & $\begin{array}{c}0,7 \\
(1,0)\end{array}$ & $\begin{array}{c}2,6 \\
(3,6)\end{array}$ & $\begin{array}{c}0,7 \\
(0,7)\end{array}$ & $\begin{array}{c}0,6 \\
(0,8)\end{array}$ & $\begin{array}{c}1,0 \\
(0,7)\end{array}$ & $\begin{array}{c}2,8 \\
(1,7)\end{array}$ & $\begin{array}{c}0,8 \\
(0,4)\end{array}$ & $\begin{array}{c}0,8 \\
(1,1)\end{array}$ \\
\hline Decapoda (larvas) & $\begin{array}{c}0,3 \\
(0,4)\end{array}$ & $\begin{array}{c}\mathbf{0 , 9} \\
(1,5)\end{array}$ & $\begin{array}{c}\mathbf{0 , 6} \\
(0,3)\end{array}$ & $\begin{array}{c}1,2 \\
(1,7)\end{array}$ & $\begin{array}{c}4,0 \\
(2,9)\end{array}$ & $\begin{array}{c}3,5 \\
(3,8)\end{array}$ & $\begin{array}{c}0,6 \\
(0,3)\end{array}$ & $\begin{array}{c}2,0 \\
(0,1)\end{array}$ \\
\hline Chaetognatha & $\begin{array}{c}\mathbf{0 , 1} \\
(0,3)\end{array}$ & $\begin{array}{c}\mathbf{0 , 4} \\
(0,5)\end{array}$ & $\begin{array}{c}\mathbf{0 , 1} \\
(0,1)\end{array}$ & ausente & $\begin{array}{c}0,6 \\
(0,6)\end{array}$ & $\begin{array}{c}1,0 \\
(1,6)\end{array}$ & $\begin{array}{c}1,0 \\
(1,1)\end{array}$ & $\begin{array}{c}0,6 \\
(0,8)\end{array}$ \\
\hline Appendicularia & $\begin{array}{c}2,8 \\
(2,6)\end{array}$ & $\begin{array}{c}8,0 \\
(9,3)\end{array}$ & $\begin{array}{c}2,5 \\
(1,9)\end{array}$ & $\begin{array}{c}1,9 \\
(1,0)\end{array}$ & $\begin{array}{c}1,9 \\
(1,8)\end{array}$ & $\begin{array}{c}3,9 \\
(4,4)\end{array}$ & $\begin{array}{c}7,5 \\
(4,4)\end{array}$ & $\begin{array}{c}1,0 \\
(1,5)\end{array}$ \\
\hline Outros & $\begin{array}{c}\mathbf{0 , 4} \\
(0,7)\end{array}$ & $\begin{array}{c}\mathbf{0 , 4} \\
(0,5)\end{array}$ & $\begin{array}{c}2,8 \\
(2,6)\end{array}$ & $\begin{array}{c}2,4 \\
(0,2)\end{array}$ & $\begin{array}{c}3,0 \\
(2,8)\end{array}$ & $\begin{array}{c}2,2 \\
(1,5)\end{array}$ & $\begin{array}{c}1,3 \\
(1,0)\end{array}$ & $\begin{array}{c}2,4 \\
(3,0)\end{array}$ \\
\hline
\end{tabular}

As espécies de copépodes que mais contribuíram para a abundância do grupo estão listadas na Tabela 4. Destacam-se em praticamente toda a área de estudo - calanóide Acartia lilljeborgi e os ciclopóides do gênero Oithona. Acartia tonsa apresentou abundância relativa inferior a $10 \%$, em média. Parvocalanus crassirostris apresentou abundância relativa mais elevada no Setor RIO, durante o inverno, e no setor SBP, durante o verão, enquanto que Paracalanus quasimodo ocorreu em maior abundância relativa nos setores BPA e LGB. Pseudodiaptomus richardi contribuiu de forma significativa para a abundância total em todos os setores e períodos do ano, com exceção do setor SBP, onde a salinidade foi mais alta do que nos demais setores. Já $P$. acutus apresentou uma menor abundância relativa nos diferentes setores, inferior a $10 \%$ em média. A contribuição relativa de Temora turbinata para a densidade total do zooplâncton foi maior no verão, especialmente nos setores BPA e LGB. Euterpina acutifrons foi em geral menos abundante do que as demais espécies de copépodes listadas. Outras espécies foram importantes isoladamente em certas estações (Tab. 4, "outros"), como Temora stylifera, Corycaeus giesbrechti e Longipedia sp. (setor SBP durante o inverno) e Centropages velificatus, Labidocera flwiatilis, Oithona simplex e Corycaeus amazonicus (setor BPA durante o verão).

\section{Distribuição espacial no inverno e no verāo}

A abundância total do zooplâncton variou entre 1682 e 82400 org. $\mathrm{m}^{-3}$ no inverno e entre 932 e 39151 org. $\mathrm{m}^{-3}$ no verão, com máximos registrados nas estações intermediárias (meso- e polihalinas) e em algumas estações da região euhalina do complexo estuarino (Fig. 4). Este resultado pode ser igualmente observado ao se comparar os valores de abundância total do zooplâncton com a salinidade (Fig. 5). Em geral, valores acima de 10000 org. $\mathrm{m}^{-3}$ ocorreram em estações com salinidade entre 17 e 26,5 (região mesoe polihalina). No entanto, os picos de abundância de inverno e verão foram registrados nas estações 20 e 16 , respectivamente, onde a salinidade era igual a 30 . A forte influência dos copépodes sobre o padrão geral de distribuição do zooplâncton é também indicada na Figura 5. 
Tabela 4. Abundância relativa média (\%) das principais espécies de copépodes coletados nos quatro setores do complexo estuarino de Paranaguá no inverno de 1993 e verão de 1994. Os desvios-padrão das médias estão indicados entre parênteses. Siglas dos setores: vide Figura 1.

\begin{tabular}{|c|c|c|c|c|c|c|c|c|}
\hline \multirow[b]{2}{*}{ Espécies/Setores } & \multicolumn{4}{|c|}{$\begin{array}{c}\text { Inyerno } \\
(\%)\end{array}$} & \multicolumn{4}{|c|}{$\begin{array}{c}\text { Verato } \\
(\%)\end{array}$} \\
\hline & $B P A$ & LGB & SBP & RIO & $\overline{B P A}$ & LGB & SBP & RIO \\
\hline Acartia tilljeborgi & $\begin{array}{l}25,1 \\
(9,5)\end{array}$ & $\begin{array}{c}24,2 \\
(23,0)\end{array}$ & $\begin{array}{l}\mathbf{2 0 , 8} \\
(6,7)\end{array}$ & $\begin{array}{c}6,4 \\
(4,4)\end{array}$ & $\begin{array}{r}11,7 \\
(7,0)\end{array}$ & $\begin{array}{c}21,1 \\
(16,6)\end{array}$ & $\begin{array}{l}11,7 \\
(5,8)\end{array}$ & $\begin{array}{c}19,7 \\
(27,8)\end{array}$ \\
\hline A. tonsa & $\begin{array}{c}\mathbf{2 , 8} \\
(5,0)\end{array}$ & $\begin{array}{c}\mathbf{5 , 0} \\
(3,8)\end{array}$ & $\begin{array}{l}1,6 \\
(2,4)\end{array}$ & $\begin{array}{c}5,9 \\
(8,4)\end{array}$ & $\begin{array}{c}9,3 \\
(15,1)\end{array}$ & $\begin{array}{c}\mathbf{8 , 0} \\
(10,0)\end{array}$ & $\begin{array}{c}\mathbf{4 , 9} \\
(6,3)\end{array}$ & $\begin{array}{c}\mathbf{0 , 9} \\
(1,3)\end{array}$ \\
\hline Paracalanus quasimodo & $\begin{array}{c}6,8 \\
(7,7)\end{array}$ & $\begin{array}{c}1,8 \\
(2,4)\end{array}$ & $\begin{array}{c}10,8 \\
(19,6)\end{array}$ & $\begin{array}{c}3,4 \\
(4,8)\end{array}$ & $\begin{array}{c}6,7 \\
(8,5)\end{array}$ & $\begin{array}{c}\mathbf{3 , 0} \\
(2,5)\end{array}$ & $\begin{array}{c}3,4 \\
(3,0)\end{array}$ & $\begin{array}{c}1,7 \\
(2,4)\end{array}$ \\
\hline Parvocalamus crassirostris & $\begin{array}{c}6,5 \\
(5,6)\end{array}$ & $\begin{array}{c}3,7 \\
(5,1)\end{array}$ & $\begin{array}{c}7,8 \\
(5,7)\end{array}$ & $\begin{array}{c}17,4 \\
(24,6)\end{array}$ & $\begin{array}{c}5,7 \\
(7,4)\end{array}$ & $\begin{array}{c}\mathbf{6 , 1} \\
(6,7)\end{array}$ & $\begin{array}{c}14,8 \\
(10,6)\end{array}$ & $\begin{array}{c}2,1 \\
(3,0)\end{array}$ \\
\hline Pseudodiaptomus acutus & $\begin{array}{c}5,5 \\
(4,1)\end{array}$ & $\begin{array}{r}6,5 \\
(5,7)\end{array}$ & $\begin{array}{c}1,3 \\
(1,2)\end{array}$ & $\begin{array}{c}6,1 \\
(8,7)\end{array}$ & $\begin{array}{c}6,4 \\
(4,8)\end{array}$ & $\begin{array}{c}9,6 \\
(8,6)\end{array}$ & $\begin{array}{c}7,0 \\
(4,0)\end{array}$ & $\begin{array}{c}4,8 \\
(6,8)\end{array}$ \\
\hline P. richardi & $\begin{array}{c}6,9 \\
(18,2)\end{array}$ & $\begin{array}{c}17,1 \\
(32,2)\end{array}$ & ausente & $\begin{array}{c}28,5 \\
(40,3)\end{array}$ & $\begin{array}{c}15,6 \\
(35,1)\end{array}$ & $\begin{array}{c}\mathbf{8 , 8} \\
(20,9)\end{array}$ & ausente & $\begin{array}{c}\mathbf{2 6 , 4} \\
(37,4)\end{array}$ \\
\hline Temora turbinata & $\begin{array}{c}\mathbf{1 8 , 8} \\
(19,8)\end{array}$ & $\begin{array}{c}10,3 \\
(12,8)\end{array}$ & $\begin{array}{c}7,5 \\
(5,5)\end{array}$ & $\begin{array}{c}7,0 \\
(9,9)\end{array}$ & $\begin{array}{c}4,6 \\
(6,5)\end{array}$ & $\begin{array}{c}2,0 \\
(3,2)\end{array}$ & $\begin{array}{c}1,8 \\
(1,9)\end{array}$ & $\begin{array}{c}\mathbf{0 , 6} \\
(0,9)\end{array}$ \\
\hline Oithona hebes & $\begin{array}{l}11,1 \\
(8,1)\end{array}$ & $\begin{array}{c}15,8 \\
(16,5)\end{array}$ & $\begin{array}{c}19,8 \\
(21,9)\end{array}$ & $\begin{array}{c}4,0 \\
(5,7)\end{array}$ & $\begin{array}{c}11,3 \\
(10,0)\end{array}$ & $\begin{array}{c}19,4 \\
(16,9)\end{array}$ & $\begin{array}{c}36,1 \\
(13,8)\end{array}$ & $\begin{array}{c}4,4 \\
(6,2)\end{array}$ \\
\hline O. oswaldocruzi & $\begin{array}{c}\mathbf{1 0 , 8} \\
(15,3)\end{array}$ & $\begin{array}{c}8,7 \\
(7,8)\end{array}$ & $\begin{array}{c}11,1 \\
(20,8)\end{array}$ & $\begin{array}{c}15,0 \\
(18,3)\end{array}$ & $\begin{array}{c}13,4 \\
(11,8)\end{array}$ & $\begin{array}{l}13,4 \\
(9,8)\end{array}$ & $\begin{array}{c}\mathbf{8 , 0} \\
(6,3)\end{array}$ & $\begin{array}{c}\mathbf{3 3}, 7 \\
(19,0)\end{array}$ \\
\hline Euterpina acutifrons & $\begin{array}{c}3,4 \\
(5,1)\end{array}$ & $\begin{array}{c}\mathbf{3 , 0} \\
(4,2)\end{array}$ & $\begin{array}{c}4,8 \\
(4,5)\end{array}$ & ausente & $\begin{array}{c}\mathbf{3 , 4} \\
(3,4)\end{array}$ & $\begin{array}{c}\mathbf{3 , 1} \\
(2,5)\end{array}$ & $\begin{array}{c}4,3 \\
(3,5)\end{array}$ & $\begin{array}{c}\mathbf{3 , 9} \\
(5,5)\end{array}$ \\
\hline Outros & $\begin{array}{c}2,5 \\
(4,4)\end{array}$ & $\begin{array}{c}4,0 \\
(5,8)\end{array}$ & $\begin{array}{l}14,3 \\
(7,5) \\
\end{array}$ & $\begin{array}{c}6,2 \\
(8,8)\end{array}$ & $\begin{array}{c}11,9 \\
(13,0)\end{array}$ & $\begin{array}{c}\mathbf{5 , 6} \\
(5,1) \\
\end{array}$ & $\begin{array}{c}8,0 \\
(6,1) \\
\end{array}$ & $\begin{array}{c}1,7 \\
(2,4)\end{array}$ \\
\hline
\end{tabular}

Os picos de abundância do zooplâncton total corresponderam aos resultados obtidos para as espécies dominantes de copépodes. As densidades elevadas observadas nas estações 10 e 20 durante o inverno (Fig. 4) foram basicamente devidas aos copépodes Acartia lilljeborgi, Temora turbinata, Oithona hebes, Pseudodiaptomus acutus e Acartia tonsa. Durante o verão, Oithona hebes foi a espécie numericamente dominante, em particular nas estações do setor SBP, mas houve uma distribuição mais eqüitativa da dominância entre as demais espécies de copépodes neste período do ano.

Para discriminar as associações zooplanctônicas nos diferentes setores do complexo estuarino de Paranaguá, foi aplicada uma análise de agrupamentos (método dos pares não ponderados - UPGA; Curi, 1983) sobre os dados de abundância dos táxons mais freqüentes, ou seja, daqueles que ocorreram em mais de $10 \%$ das amostras. Quatro grupos principais de espécies foram obtidos (Fig. 6a). O primeiro (grupo A) foi constituído por apenas uma espécie, o copépode Pseudodiaptomus richardi, que é o organismo dominante nas estações internas. $\mathrm{O}$ grupo B incluiu as espécies Acartia tonsa, Oithona oswaldocruzi, $O$. hebes e Oikopleura dioica, que foram mais abundantes nas estações intermediárias (regiões meso- e polihalinas), geralmente em salinidades variando de 17 a 25 . Outras espécies que ocorreram nesta faixa de salinidade, mas com maiores concentrações nas águas mais salinas, formaram o grupo C. No entanto, Arcatia lilljeborgi e Pseudodiaptomus acutus, geralmente mais abundantes nas estações intermediárias, foram associados a este grupo, provavelmente devido aos altos valores de abundâncias destas espécies na estação 20 (foz do Rio Guaraguaçu), onde a salinidade chegou a 30 . Finalmente, observou-se uma última associação (grupo D), formada por espécies que ocorreram quase que exclusivamente nas estações mais externas, com salinidade superior a 25. A única exceção neste caso foi o cladócero Penilia avirostris, que também foi abundante nas estações intermediárias dos setores LGB e SBP durante o verão.

Os dados de abundância do zooplâncton foram também utilizados para separar as estações de coleta através da análise de agrupamentos. Quatro grupos de estações foram obtidos (Fig. 6b). Estes grupos de estações podem ser diretamente relacionados com os grupos de espécies mostrados na Figura 6a. O grupo A foi formado pelas estações mais internas dos quatro setores amostrados, onde o copépode Pseudodiaptomus richardi foi o componente dominante do zooplâncton. Estas estações representam a região oligohalina do complexo estuarino. $\mathrm{O}$ grupo $\mathrm{B}$ de estações correspondeu aos setores mesohalinos, com salinidade variando em geral de 5 a 20, onde dominaram Acartia tonsa, 
Oithona oswaldocruzi, O. hebes e Oikopleura dioica, do grupo $\mathrm{B}$ descrito acima, além de Acartia lilljeborgi e Pseudodiaptomus acutus. As estações do grupo C podem ser interpretadas como a região polihalina do estuário, com salinidades geralmente entre 20 e 30 , dominada pelas espécies do grupo C (Labidocera fluviatilis, Euterpina acutifrons, Parvocalanus crassirostris, Temora turbinata, além de Acartia lilljeborgi e Pseudodiaptomus acutus, entre outras). $\mathrm{O}$ grupo $\mathrm{D}$ corresponde às estações do setor euhalino, com salinidades em torno de 30 ou superiores, onde ocorreram espécies típicas da plataforma continental, como por exemplo, Temora stylifera, Clausocalanus furcatus, Calanopia americana e Paracalanus aculeatus (grupo D da Fig. 6a). É interessante notar que a estação 16 , a mais externa do setor SBP, não foi associada de forma significativa com nenhum dos grupos de estações indicados na Figura 6b, provavelmente porque nela ocorreram, em grande número, organismos pertencentes a quase todos os grupos de espécies (com exceção do grupo A). Situação semelhante foi observada para a estação 21 , situada no Rio Itiberê em Paranaguá, onde 0 zooplâncton foi constituído basicamente por espécies dos grupos C e D.

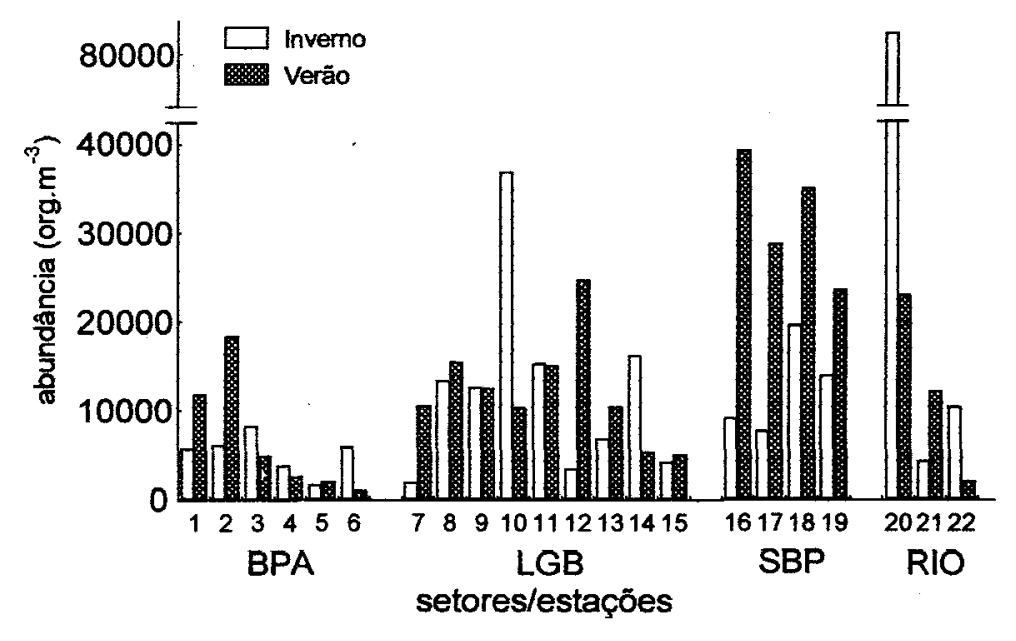

Fig. 4. Abundância total do zooplâncton durante julho/1993 (inverno) e fevereiromarço/1994 (verão) nas estações de coleta dos diferentes setores do complexo estuarino de Paranaguá Siglas dos setores: vide Figura 1.

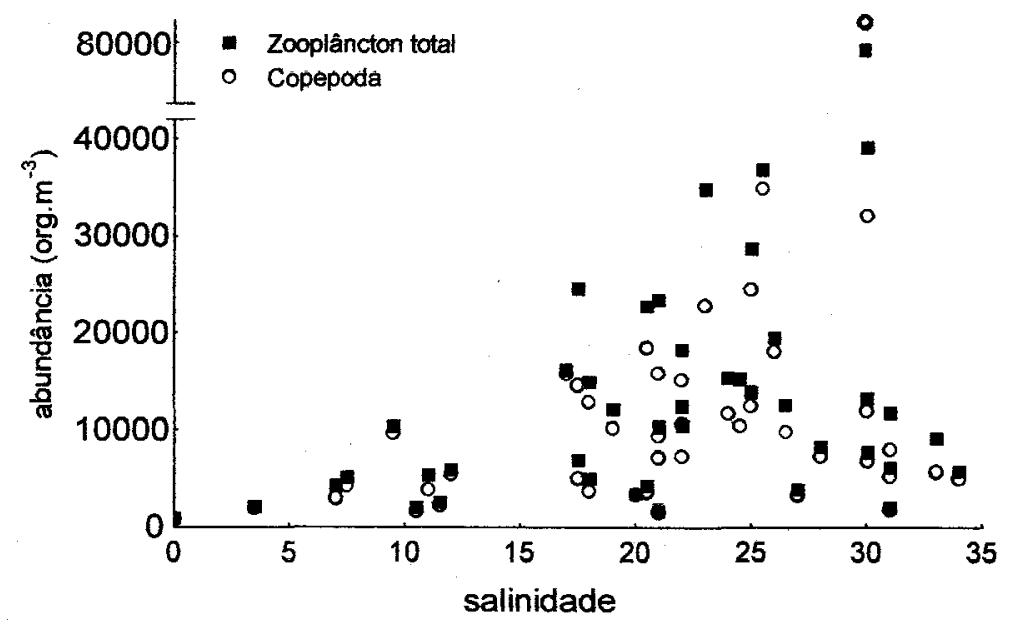

Fig. 5. Abundância do zooplâncton total (quadrados) e dos copépodes (círculos) em relação ao gradiente de salinidade. Valores referentes a julho/1993 (inverno) e fevereiro-março/1994 (verão). 

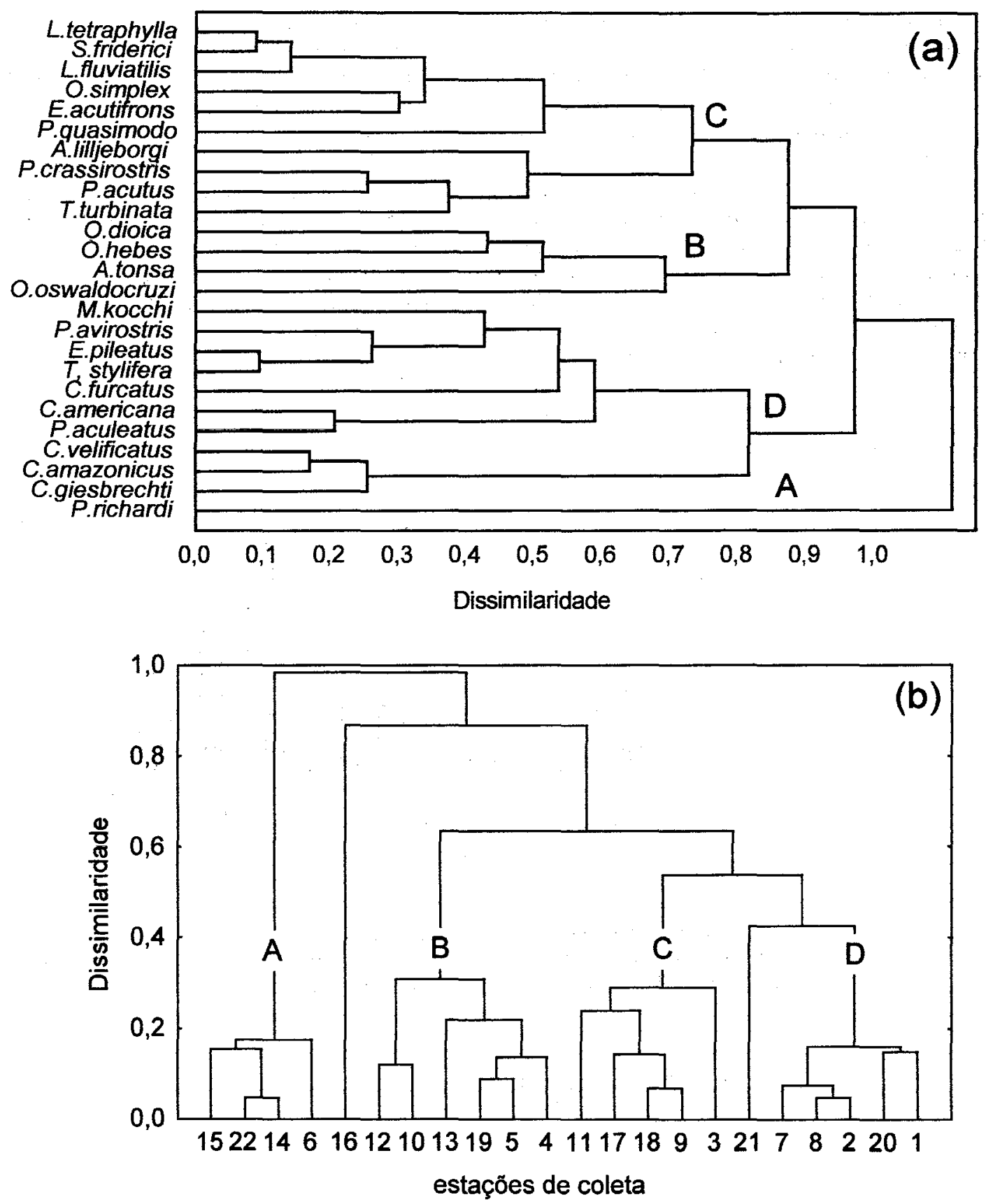

Fig. 6. Resultados da análise de classificação das associações zooplanctônicas (a) e das estações de coleta (b) do complexo estuarino de Paranaguá. As letras A, B, C e D indicam os grupos de espécies e estações. Ambos os agrupamentos foram obtidos a partir dos valores de abundância das espécies dominantes do zooplâncton.

\section{Discussão}

\section{Composição específica e abundância relativa}

A composição do zooplâncton no complexo estuarino de Paranaguá é similar à encontrada na região de Cananéia-Iguape (Tundisi, 1972; Por et al., 1984; Almeida Prado-Por et al., 1989) e em outros estuários da costa sudeste (Almeida Prado \& Lansac Tôha, 1984; Rocha, 1986; Lopes, 1994). A dominância numérica dos copépodes, que chegam a atingir mais de $90 \%$ do zooplâncton total, é uma regra geral não só para os estuários brasileiros, mas para a maioria dos ecossistemas estuarinos mundiais (Miller, 1983; Day et al., 1989). Os gêneros Acartia, Pseudodiaptomus e Oithona estão entre os mais importantes nos estuários tropicais e subtropicais do Atlântico Sudoeste (Björnberg, 1981). Em conjunto com Temora, Paracalanus e Parvocalanus, estes foram os gêneros de copépodes mais abundantes no complexo estuarino de Paranaguá. 
Os tintiníneos foram outro componente importante do zooplâncton no complexo estuarino de Paranaguá, ainda mais considerando que os valores de abundância relativa e absoluta deste grupo foram provavelmente subestimados em uma proporção não definida. Os tintiníneos e outros protistas tecados não são capturados quantitativamente com a rede de 63 $\mu \mathrm{m}$; redes com abertura menor que $35 \mu \mathrm{m}$ são mais adequadas para a coleta destes organismos (Omori \& Ikeda, 1984). Em ordem decrescente de importância numérica para 0 zooplâncton total encontram-se as apendiculárias (Oikopleura dioica), os cladóceros (Penilia e Evadne) e os quetognatos (Sagitta friderici) entre os organismos holoplanctônicos, além das larvas de cirripédios, gastrópodes, decápodes, poliquetas e bivalves. Estes são em geral os táxons subdominantes na maioria dos estuários brasileiros (Neumann-Leitão, 1994/95).

O copépode Temora turbinata nunca havia sido registrado no Brasil até meados da década de 1980. Temora stylifera era a única espécie do gênero conhecida em águas brasileiras até então (Björnberg, 1981). Atualmente T. turbinata parece encontrar-se em processo de dispersão por praticamente toda a plataforma continental brasileira, pois os relatos de sua ocorrência têm sido cada vez mais freqüentes desde que Araújo \& Montú (1993) a observaram pela primeira vez em estuários de Sergipe, em amostras coletadas nos anos de 1985 e 1986. EskinaziSant'Anna \& Björnberg (1995)* citam a espécie para os litorais de São Paulo, Espírito Santo e Bahia, e Muxagata \& Gloeden (1995) a registraram no estuário da Lagoa dos Patos. Outros registros ainda não publicados incluem a plataforma continental entre Cabo Frio e Cabo de São Tomé (obs. pess.) e estuários de Pernambuco (M.N. Paranaguá, obs. pessoal). Amostras obtidas na Baía de Paranaguá em 1991 também continham muitos exemplares da espécie (obs. pess.). Basicamente duas hipóteses podem ser consideradas para explicar a ocorrência de Temora turbinata na costa brasileira nos últimos 1015 anos:

1) A espécie foi introduzida em águas costeiras ou estuarinas do Brasil por intermédio da água de lastro de navios. Carlton \& Geller (1993) mencionam uma série de casos de dispersão de organismos planctônicos através deste mecanismo de transporte.

2) Populações de Temora turbinata foram trazidas através de correntes marinhas desde o Mar do Caribe até a costa brasileira. Apesar do padrão de circulação predominante da Corrente Norte do Brasil (Richardson et al., 1994; Stramma et al., 1995)

(*) Eskinazi-Sant'anna, E. M. \& Björnberg, T. K. S. Sobre a corrência de Temora turbinata (Dana, 1859) em águas costeiras e de plataforma do Brasil. In: CONGRESSO LATINOAMERICANO DE CIENCIAS DEL MAR, 6. Mar del Plata, 1995. Resumos. Mar del Plata, Univesidad Nacional de Mar del Plata. p. 73 constituir uma forte barreira hidrográfica para o transporte de populações planctônicas no sentido norte-sul na altura do equador, a troca de populações desta espécie através de regiões oceânicas é perfeitamente possível e parece ocorrer no Mar da Tasmânia, entre a Austrália e a Nova Zelândia (Bradford, 1977). Seja qual for a explicação, as populações de Temora turbinata aqui introduzidas tiveram uma rápida dispersão porque vive em águas tropicais e subtropicais com características físicoquímicas similares às encontradas na plataforma continental brasileira (Gonzalez \& Bowman, 1965; Vervoort, 1965; Bradford, op. cit.; Paffenhöfer, 1985).

A composição do zooplâncton apresentou diferenças importantes em relação aos dados obtidos em 1980/81 por Montú \& Cordeiro (1998). Como até o momento este era o único trabalho a abordar de forma mais detalhada o zooplâncton do complexo estuarino de Paranaguá, a discussão que se segue é fortemente baseada nele.

Segundo Montú \& Cordeiro (op. cit.), as espécies dominantes do zooplâncton na Baía de Paranaguá foram os copépodes Acartia lilljeborgi, Oithona oswaldocruzi e Euterpina acutifrons. No presente estudo, estas espécies ocorreram em alta densidade, mas outras também foram abundantes, até mesmo superando-as numericamente.

O copépode calanóide Acartia tonsa foi encontrado em setores mesohalinos e polihalinos também amostrados por Montú \& Cordeiro (op. cit.), que, no entanto, não o registraram em seu levantamento. Isto pode ter ocorrido por uma falha na identificação dos indivíduos adultos desta espécie, que podem ser eventualmente confundidos com juvenis de Acartia lilljeborgi. Problemas similares ocorreram com a identificação dessas e outras espécies coletadas na região de Cananéia-Iguape até meados da década de 80 (Almeida Prado-Por et al., 1989).

Oithona hebes também domina no complexo estuarino de Paranaguá, tendo sido registrada antes como $O$. ovalis. Esta não foi uma das espécies dominantes do zooplâncton em 1980/81, sendo substituída por $O$. oswaldocruzi em praticamente toda a extensão do estuário. No entanto, estes resultados também suscitam algumas dúvidas, pois a taxonomia das espécies estuarinas do gênero Oithona era de certa forma confusa até a revisão de Rocha (1986). Neste trabalho, demonstrou-se que $O$. ovalis e $O$. oligohalina são sinônimos de $O$. hebes e $O$. oswaldocruzi, respectivamente.

Parvocalanus crassirostris é outra espécie dominante de copépode não registrada anteriormente por Montú \& Cordeiro (op. cit.), talvez porque a rede com malha de $180 \mu \mathrm{m}$ utilizada não capturou de forma adequada os copepoditos e náuplios desta espécie, assim como descrito aqui para a rede de 300 $\mu \mathrm{m}$. No entanto, é dificil explicar porque a rede de 
$180 \mu \mathrm{m}$ capturou grandes quantidades de Oithona oswaldocruzi e não reteve nenhum indivíduo de Parvocalanus crassirostris, sendo que estas espécies possuem tamanhos semelhantes (Björnberg, 1981).

$\mathrm{O}$ registro inédito de Pseudodiaptomus richardi para o complexo estuarino de Paranaguá, feito no presente trabalho, deve-se às amostragens nos setores mais internos, onde a salinidade foi bem menor do que os mínimos verificados por Montú \& Cordeiro (1988).

Finalmente, observou-se que Sagitta tenuis foi a única espécie de Chaetognatha listada por Montú \& Cordeiro (op. cit.) para o complexo estuarino de Paranaguá. É possível que os autores tenham se baseado no trabalho de Boltovskoy (1981), que considera Sagitta friderici sinômino de $S$. tenuis, para identificar as espécies deste grupo. No presente estudo foram adotados os critérios de Almeida Prado (1961), que trata ambas espécies como válidas em função de uma série de características morfológicas, sendo as mais importantes o número de dentes na armadura bucal, o número de ganchos mandibulares e principalmente o número, tamanho e posição dos ovulos nos indivíduos adultos. Dada a ampla dominância de Sagitta friderici em relação a $S$. tenuis no complexo estuarino de Paranaguá, é provável que a primeira tenha sido a espécie efetivamente encontrada por Montú \& Cordeiro (op. cit.) ou que individuos das duas espécies tenham sido agrupados como Sagitta tenuis naquela ocasião.

\section{Grupos de espécies e distribuição espaço-temporal}

A classificação das associações zooplanctônicas através de métodos analíticos (agrupamentos), pode ser combinada com os critérios descritivos de Jeffries (1967), baseados na relação entre as densidades numéricas das espécies e a faixa de salinidade na qual são encontradas.

A única espécie que ocorreu preferencialmente em salinidades inferiores a 15 foi o copépode Pseudodiaptomus richardi (grupo $\mathrm{A}$ da análise de agrupamentos), que representa portanto o componente tipicamente estuarino do zooplâncton na área de estudo, coincidindo com a distribuição da espécie em outros estuários brasileiros (Almeida Prado-Por \& Lansac-Tôha, 1984).

Acartia tonsa, Oithona oswaldocruzi e $O$. hebes (grupo B) podem ser consideradas espécies estuarinomarinhas por terem sido encontradas em uma ampla faixa de salinidade. Certamente têm mais afinidade pelos setores mesohalinos e polihalinos do estuário, uma vez que a abundância destas espécies é menor em salinidades maiores que 25 , sugerindo que suas populações são mantidas basicamente por recrutamento local. A apendiculária Oikopleura dioica, também classificada no grupo $\mathrm{B}$, pode ser considerada uma espécie estuarino-marinha, visto que sua distribuição espacial foi muito semelhante a $O$. hebes e $A$. tonsa. Nota-se, porém, que esta espécie é abundante nas águas costeiras da região (Tundisi, 1970), o que mostra seu alto grau de adaptação ao gradiente de salinidade e às variações espaciais na concentração de material particulado. Nogueira et al. (1988) e Machado (1995) verificaram que os picos de abundância de $O$. dioica podem ocorrer tanto na entrada como nas áreas internas da Baía de Guanabara, coincidindo com os resultados aqui obtidos.

É interessante observar que Acartia tonsa parece desenvolver-se melhor em salinidades intermediárias não só no complexo estuarino de Paranaguá como também na região de Cananéia-Iguape (Almeida Prado-Por et al., 1989). No entanto, vários trabalhos têm mostrado a ocorrência preferencial de $A$. tons $a$ em altas salinidades, como no estuário da Lagoa dos Patos (Duarte, 1986; Montú, 1980), nas águas costeiras do sul do Brasil (var. cryophila, Björnberg, 1963), ao longo da costa uruguaia e argentina (Sabatini, 1990; Fernández Aráoz, 1991; Fernández Aráoz et al., 1994) e no Estreito de Magalhães, limite meridional de distribuição da espécie (Guglielmo \& Ianora, 1995). Este fato aponta a necessidade de estudos mais detalhados, combinando técnicas de taxonomia descritiva e biologia molecular, para determinar as variações genotípicas e fenotípicas das populações de $A$. tonsa encontradas neste setor do Atlântico. Estes estudos poderão verificar se Acartia tonsa representa na verdade um complexo de espécies assemelhadas, ou se as diferenças de distribuição encontradas refletem estratégias adaptativas de diferentes populações da mesma espécie. Informações a respeito do seu comportamento alimentar poderão ser igualmente úteis para o melhor entendimento de sua distribuição na costa sul do Brasil. Acartia tonsa não está adaptada a baixas concentrações de material particulado em suspensão e parece interromper os movimentos de filtração quando a concentração de clorofila- $a$ é inferior a $1 \mu \mathrm{g} \mathrm{I}^{-1}$ (Paffenhöfer \& Stearns, 1988). Concentrações iguais ou inferiores a esta são a regra para as águas de plataforma ao norte da Ilha de Santa Catarina, mas a influência $\mathrm{da}$ drenagem dos estuários do rio da Prata e da Lagoa dos Patos faz com que valores de até $3,5 \mu \mathrm{g} \mathrm{l}^{-1}$ sejam observados mais ao sul (Brandini, 1990), permitindo o estabelecimento de $A$. tonsa naquela região.

Apesar de Acartia lilljeborgi e Pseudodiaptomus acutus terem sido incluídas no grupo $\mathrm{C}$ da análise de agrupamento, também podem ser consideradas espécies estuarino-marinhas, pois ocorreram populações autóctones nos setores meso- e polihalinos, conforme sugerem as altas densidades de náuplios observadas nestes locais (dados não apresentados). Este não é o caso de Temora turbinata, Labidocera fluviatilis, Oithona simplex, Parvocalanus crassirostris, Paracalanus quasimodo 
e Euterpina acutifrons, espécies que foram algumas vezes encontradas em concentrações altas nas áreas meso- e polihalinas, mas que aparentemente dependem de recrutamento adicional a partir da região costeira adjacente para a manutenção dos estoques populacionais. Portanto, estas espécies devem ser consideradas marinho-eurihalinas no presente caso (grupo C). Pelos mesmos motivos, outros organismos holoplanctônicos importantes em termos numéricos, como Sagitta friderici, Liriope tetraphylla e os tintiníneos (como um grupo) são aqui tratados como marinho-eurihalinos. Por fim, foram encontradas relativamente poucas espécies marinhoestenohalinas de copépodes (grupo D), incluindo Calanopia americana, Paracalanus aculeatus, Clausocalanus furcatus, Eucalanus pileatus e Centropages velificatus, entre outras. Também podem ser incluidas neste grupo as espécies Temora stylifera, Corycaeus spp. e Oncaea spp., já que todas estas estiveram restritas às estações mais externas, em salinidade nunca inferior a 25 . Deve-se ressaltar que outras espécies marinho-estenohalinas foram encontradas em um estudo sobre a variação sazonal do zooplâncton na entrada da Baía de Paranaguá (Lopes, 1997).

Com pequenas variações, a distribuição espacial da maioria das espécies de copépodes e de outros táxons holoplanctônicos dominantes na área estudada foi semelhante à encontrada em outros estuários brasileiros, especialmente no que se refere à influência da salinidade sobre a estrutura das associações zooplanctônicas (Montú, 1980; Almeida Prado-Por \& Lansac-Tôha, 1984; Lansac-Tôha, 1985; Lopes et al., 1986; Almeida Prado-Por et al., 1989; Lopes, 1994; Neumann-Leitão, 1994; Bonecker, 1995; Araújo, 1996). Quanto aos táxons meroplanctônicos, não é possivel tecer aqui maiores comentários, pelo fato de não terem sido identificados ao nível de espécie neste e nos demais estudos sobre a distribuição espaço-temporal do zooplâncton realizados até o momento no Brasil.

De acordo com Sandercock (1967), a segregação espacial, as diferenças de tamanho e a separação sazonal são os mecanismos básicos que possibilitam a coexistência de espécies congenéricas do zooplâncton. Estas espécies supostamente ocupam nichos ecológicos semelhantes e, portanto, competem por recursos similares. A segregação espacial de espécies congenéricas de Pseudodiaptomus foi nítida no complexo estuarino de Paranaguá. Entretanto, no caso de outros gêneros dominantes de copépodes, como Acartia e Oithona, outros argumentos devem ser ponderados. Baseando-se nas medidas fornecidas por Björnberg (1981), pode-se considerar que as diferenças de tamanho são significativas entre Oithona simplex e as demais espécies do gênero aqui encontradas. O mesmo não é válido para Acartia spp. e entre Oithona hebes e $O$. oswaldocruzi. A hipótese de separação sazonal também não é convincente, pois estas espécies coexistiram tanto no inverno quanto no verão, embora as abundâncias de Acartia tonsa tenham sido ligeiramente maiores no periodo mais quente do ano. Mesmo considerando que houve alguma segregação espacial entre estas espécies congenéricas, principalmente nos extremos inferior e superior do gradiente de salinidade, a sobreposição espaço-temporal foi muito mais comum.

As espécies estuarino-marinhas de copépodes apresentaram densidades máximas nos setores intermediários do complexo estuarino de Paranaguá, padrão que coincidiu aproximadamente com a distribuição espacial da clorofila- $a$. Brandini (1985) e Brandini et al. (1988) sugeriram que as maiores concentrações de clorofila- $a$ ocorrem nos setores intermediários da baía devido ao equilíbrio entre a disponibilidade de nutrientes e a turbidez. Em outras palavras, a produção primária do fitoplâncton seria limitada pela luz nas áreas internas e pelo nitrogênio nas áreas mais externas. As menores razões $\mathrm{N} / \mathrm{P}$ nos setores externos da baía dão apoio adicional a esta idéia (Brandini, op. cit.; Machado et al., 1996). Quanto ao zooplâncton, quais seriam os mecanismos que favorecem as altas concentrações de organismos nos setores intermediários deste complexo estuarino? Poucas evidências têm sido encontradas que suportem a simples hipótese de que os perfis verticais de biomassa algal e do zooplâncton são mutuamente relacionados no oceano aberto (Longhurst \& Harrison, 1989) e certamente a mesma dificuldade de interpretação existe em relação aos gradientes horizontais estuarinos. Com base nos resultados obtidos, é difícil estabelecer uma relação causal entre as altas concentrações de clorofila- $a$ e a abundância do zooplâncton nas regiões meso- e polihalinas.

Segundo Miller (1983), nos estuários parcialmente misturados pode existir um ponto "nulo" de circulação onde, durante as sizígias, uma determinada porção de água vinda de sua posição original no pico da maré cheia não consegue mais fluir em direção à saída do estuário no pico da maré baixa, e assim acaba retornando para o interior do estuário no próximo ciclo de maré. Abaixo deste ponto nulo há uma mistura significativa da água costeira com a água salobra e a composição do plâncton é similar àquela encontrada na plataforma continental ao largo do estuário. A montante do ponto nulo de circulação é possível o desenvolvimento e a manutenção de populações autóctones adaptadas às amplas flutuações da salinidade (Bousfield et al., 1975; Miller, op. cit.). No complexo estuarino de Paranaguá, este provável ponto de nulo de circulação, apesar de variar sazonalmente, deve estar situado em salinidades entre 17 e 25 , que representam os limites para a penetração das espécies marinho-eurihalinas de copépodes como Temora turbinata, Paracalanus quasimodo, Oithona simplex e Euterpina acutifrons. Portanto, é possível que os máximos de abundância do zooplâncton observados justamente nesta faixa de 
salinidade estejam associados à persistência das populações em uma massa d'água que, embora de alta mobilidade, minimiza a possibilidade de expatriação dos animais para a região costeira adjacente.

\section{Agradecimentos}

Os autores agradecem à CAPES e ao Curso de Pós-Graduação em Zoologia da UFPR pelo financiamento parcial deste projeto de pesquisa.

\section{Referências bibliográficas}

Almeida Prado, M. S. 1961. Disł -ibuição dos Chaetognatha no Atlântico Sul ocidental. Bolm Inst. oceanogr., S Paulo, 11(4):15-49.

Almeida Prado, M. S. 1972. Mysidacea (Crustacea) da região lagunar de Cananéia. Tese de doutorado. Universidade de São Paulo, Instituto de Biociências. 86p.

Almeida Prado-Por, M. S. \& Lansac Tôha, F. A. 1984. The distribution of brackish water Calanoida (Copepoda) along the coasts of Brazil. Hydrobiologia, 113:147-150.

Almeida Prado-Por, M. S.; Pompeu, M. \& Por, F. D. 1989. The impact of Valo Grande canal on the planktonic copepod populations of the Mar Pequeno Seaway (São Paulo). In: Spanier, Y.; Steinberg, S.; Luria, M. eds ISEEQS Pub. Jerusalem: Environmental quality and ecosystem stability. p. 205-217.

Almeida, M. V. O. \& Spach, H. L. 1992. Ictioplâncton do litoral do Paraná/Brasil - Uma revisão. Arq. Biol. Tecnol., 35(2):221-238.

Araújo, H. M. P. 1996. Zooplâncton do estuário dos Rios Piauí e Fundo (Sergipe, Brasil): flutuações espaciais, sazonais e tidais. Tese de doutorado. Universidade Federal do Paraná. 191p.

Araújo, H. M. P. \& Montú, M. 1993. Novo registro de Temora turbinata (Dana, 1849) (Copepoda, Crustacea) para águas atlânticas. Nauplius, 1:8990.

Björnberg, T. K. S. 1963. On the marine free-living copepods off Brazil. Bolm Inst. oceanogr., S Paulo, 13(1):3-142.
Björnberg, T. K. S. 1981. Copepoda. In: Boltovskoy, D. ed. Atlas del zooplancton del Atlantico Sudoccidental y métodos de trabajo com el zooplancton marino. Mar del Plata, INIDEP. p.587-602.

Boltovskoy, D. 1981. Atlas del zooplancton del Atlántico Sudoccidental y métodos de trabajo con el zooplancton marino. Mar del Plata, INIDEP. 936p.

Bonecker, S. L. C. 1995. Dinâmica do zooplâncton no sistema estuarino do Rio Mucuri (BA). Tese de doutorado. Universidade de São Paulo, Instituto de Biociências. 154p.

Bousfield, E. L.; Filteau, G.; O'neill, M. \& Gentes, P. 1975. Population dynamics of zooplankton in the middle St. Lawrence estuary. In: Cronin, L. E. ed. Estuarine research. New York, Academic Press. p. 325-351.

Bradford, J. M. 1977. Distribution of the pelagic copepod Temora turbinata in New Zealand coastal waters, and possible Trans-Tasman population continuity. N. Z. J. mar. Freshwater Res., 11(1):131-144.

Brandini, F. P. 1985. Ecological studies in the Bay of Paranaguá. I. Horizontal distribution and seasonal dynamics of the phytoplankton. Bolm Inst. oceanogr., S Paulo, 33(2):139-147.

Brandini, F. P.; Moraes, C. L. B. \& Thamm, C. A 1988. Shelf break upwelling, subsurface maxima of chlorophyll and nitrite, and vertical distribution of a subtropical nano- and microplankton community off southeastern Brazil. In: ENCONTRO BRASILEIRO DE PLÂNCTON, 3. Caiobá, PR, 1988. Memórias. Curitiba, UFPR. p.47-56.

Brandini, F. P. 1990. Hydrography and characteristics of the phytoplankton in shelf and oceanic waters off southeastern Brazil during winter (July/August 1982) and summer (February/March 1984). Hydrobiologia, 196:111-148.

Carlson, D. M. 1978. The ecological role of zooplankton in a Long Island salt marsh. Estuaries, 1(2):85-92.

Carlton, J. T. \& Geller, J. B. 1993. Ecological roulette: the global transport of nonindigenous marine organisms. Science, 261(5117):78-82.

Curi, P. R. 1983. Análise de agrupamento: métodos seqüenciais, aglomerativos e hierárquicos. Ciência Cult., 35(10):1416-1429. 
Dam, H. G. \& Peterson, W. T. 1993. Seasonal contrasts in the diel vertical distribution, feeding behavior, and grazing impact of the copepod Temora longicornis in Long Island Sound. J. mar. Res., 51:561-594.

Day Jr., J. W.; Hall, C. A. S.; Kemp, W. M. \& YáñezArancibia, A. 1989. Estuarine ecology. New York, John Wiley \& Sons. 558 p.

Duarte, A. K. 1986. Distribuição, abundância e flutuações sazonais do copépodo calanóide Acartia tonsa na enseada estuarina Saco do Justino e canal do estuário da Lagoa dos Patos (RS-Brasil). Dissertação de mestrado. Fundação Universidade do Rio Grande. 102p.

Fernández Aráoz, N. C. 1991. Individual biomass, based on body measures of copepod species considered as main forage items for fishes of the Argentine shelf. Oceanol. Acta, 14(6):575580 .

Fernández Aráoz, N. C.; Santos, B. A. \& Ramírez, F. C. 1994. Analisis ecológico de la distribución de los copépodos planctonicos de una campaña de primavera, en la Zona Comun de Pesca. Frente Maritimo, 15:133-140.

Frontier, S. 1981. Diseño de muestreos. In: Boltovskoy, D. ed. Atlas del zooplancton del Atlántico Sudoccidental y métodos de trabajo con el zooplancton marino. Mar del Plata, INIDEP. p.103-108.

Godefroid, R. S. 1997. Estrutura da comunidade de peixes na zona de arrebentação da praia de Pontal do Sul, Paraná Dissertação de mestrado. Universidade Federal do Paraná. 129p.

Gonzalez, J. G. \& Bowman, T. 1965. Planktonic copepods from Bahia Fosforecente, Puerto Rico, and adjacent water. Proc. U.S. natn. Mus., 117:241-304.

Guglielmo, L. \& Ianora, A. eds 1995. Atlas of marine zooplankton straits of Magellan: copepods. Berlin, Springer-Verlag. 279p.

Heinle, D. R. 1966. Production of a calanoid copepod, Acartia tonsa, in the Patuxent River Estuary. Chesapeake Sci., 7(2):59-74.

Jeffries, J. P. 1967. Saturation of zooplankton by congeneric associattes. In: Lauff, G.H. ed. Estuaries. Washington, American Association Advancement of Science, 83:500-508.
Lansac-Tôha, F. A 1985. Ecologia do zooplâncton do estuário do Rio Una do Prelado (São Paulo, Brasil). Tese de doutorado. Universidade de São Paulo, Instituto Oceanográfico. 195p.

Longhurst, A R. \& Harrison, W. G. 1989. The biological pump: profiles of plankton production and consumption in the upper ocean. Prog. Oceanogr., 22(1):47-123.

Lopes, R. M. 1994. Zooplankton distribution in the Guaraú River Estuary (Southeastern Brazil). Estuar. coast. Shelf Sci., 39(3):287-302.

Lopes, R. M. 1997. Distribuição espacial, variação temporal e atividade alimentar do zooplâncton no complexo estuarino de Paranaguá. Tese de doutorado. Universidade Federal do Paraná. 140p.

Lopes, R. M.; Almeida-Prado-Por, M. S. \& Por, F. D. 1986. Zooplankton seasonality in the Rio Verde estuary (Juréia, São Paulo, Brazil). Rev. Hydrobiol. trop., 19(3-4):207-214.

Machado, C. F. 1995. Composição e variação espaçotemporal da Classe Appendicularia (Tunicata) na Baía de Guanabara - RJ, Brasil. Monografia de Bacharelado. Universidade Federal do Rio de Janeiro, 50p.

Machado, E. C.; Daniel, C. B.; Brandini, N. \& Queiroz, R. L. V. (no prelo). Temporal and spatial dynamics of nutrients and particulate suspended matter in Paranaguá Bay, PR, Brazil. Nerítica, 11.

Mauchline, J. 1998. The biology of calanoid copepods. London, Academic Press. 692p.

Miller, C. B. 1983. The zooplankton of estuaries. In: Ketchum, B. H. ed. Estuaries and enclosed seas. New York, Elsevier Sci. Publ. p. 103-149.

Montú, M. 1980. Zooplâncton do estuário da Lagoa dos Patos. I. Estrutura e variações temporais e espaciais da comunidade. Atlântica, Rio Grande, 4:53-72.

Montú, M. \& Cordeiro, T. A. 1988. Zooplancton del complejo estuarial de la Bahia de Paranaguá. I. Composición, dinámica de las especies, ritmos reproductivos y acción de los factores ambientales sobre la comunidad. Nerítica, 3(1):61-83.

Muxagata E. \& Gloeden, I. M. 1995. Ocorrência de Temora turbinata Dana 1849 (Crustacea: Copepoda) no estuário da Lagoa dos Patos, RS, Brasil. Nauplius, 3:163-164. 
Neumann-Leitão, S. 1994. Impactos antrópicos na comunidade zooplanctônica estuarina. Porto de Suape - PE - Brasil. Tese de doutorado. Universidade de São Paulo, Escola de Engenharia de São Carlos. 273p.

Neumann-Leitão, S. 1994/1995. Resenha literária sobre zooplâncton estuarino no Brasil. Trabhs. Oceanogr., Univ. Fed. Pernambuco, 23:25-53.

Nicolajsen, H. F., Møhlenberg, F. \& Kiørboe, T. 1983. Algal grazing by the planktonic copepods Centropages hamatus and Pseudocalanus sp.: diurnal and seasonal variation during the spring phytoplankton bloom in the Øeresund. Ophelia, 22(1):15-31.

Nogueira, C. R.; Bonecker, A. C. T. \& Bonecker, S. L. C. 1988. Zooplâncton da Baía de Guanabara (RJ - Brasil): Composição e variações espaço-temporais. In: ENCONTRO BRASILEIRO DE PLÂNCTON, 3. Caiobá, PR, 1988. Memórias. Curitiba, UFPR. p.151156.

Omori, M. \& Ikeda, T. 1984. Methods in marine zooplankton ecology. New York, John Wiley \& Sons. 332p.

Paffenhöfer, G. -A. 1985. The abundance and distribution of zooplankton on the Southeastern shelf of the United States. In: Atkinson, L. P.; Menzel, D. W. \& Bush, K. A. eds Oceanography of the southeastern U. S. continental shelf. Coast. estuar. Sci., 2:104-117.

Paffenhöfer, G.-A. \& Stearns, D. E. 1988. Why is Acartia tonsa (Copepoda:Calanoida) restricted to nearshore environments? Mar. Ecol. Prog. Ser., 42(1):33-38.

Parsons, T. R.; Maita, Y. \& Lalli, C.M. 1984. A manual of chemical and biological methods for seawater analysis. Oxford, Pergamon Press. $173 p$.

Por, F. D.; Almeida Prado-Por, M. S. \& Oliveira, E. C. 1984. The mangal of the estuary and lagoon system of Cananéia (Brazil). In: Por, F. D. \& Dor, I. eds Hydrobiology of the mangal. Boston, Junk/ The Hague. p.211-228.

Richardson, P. L.; Hufford, G. E.; Limeburger, R. \& Brown, W. S. 1994. North Brazil Current retroflection eddies. J. geophys. Res., 99(C3):5081-5093.
Rocha, C. D. L. 1994. Crescimento, mortalidade e produção do Copepoda Acartia tonsa Dana, 1848, na enseada estuarina do Saco do Justino, Lagoa dos Patos (RS - Brasil) - Verão de 1994. Monografia de Bacharelado. Fundação Universidade do Rio Grande. 44p.

Rocha, C. E. F. 1986. Copepods of the genus Oithona Baird, 1843 from mangrove areas of Central and South America. Hydrobiologia, 135:95-107.

Sabatini, M. E. 1990. The developmental stages (copepodids I to VI) of Acartia tonsa Dana, 1849 (Copepoda, Calanoida). Crustaceana, 59(1):53-61.

Sandercock, G. A. 1967. A study of selected mechanisms for the coexistence of Diaptomus spp. in Clarke Lake, Ontario. Limnol. Oceanogr., 12:97-112.

Sinque, C. 1989. Ictioplâncton do ecossistema da Baía de Paranaguá (Paraná-Brasil). Arq. Biol Tecnol, 32(3):473-490.

Sinque, C.; Koblitz, S. \& Costa, L. M. 1982. Ictioplâncton do complexo estuarino - Baia de Paranaguá e adjacências $\left(25^{\circ} 10^{\prime} \mathrm{S} 48^{\circ} 10^{\prime} \mathrm{W}-25^{\circ}\right.$ $\left.35^{\prime} \mathrm{S} 48^{\circ} 45^{\prime} \mathrm{W}\right)$ Paraná, Brasil. I. Aspectos gerais. Arq. Biol. Tecnol., 25(3/4):279-300.

Sinque, C.; Costa, L. M.; Koblitz, S. \& Maia, J. C. S. 1983. Ichthyoplankton surveys in the estuarine Bay of Paranaguá, and surroundings areas $\left(25^{\circ} 10^{\prime} \mathrm{S} 48^{\circ} 10^{\prime} \mathrm{W}-25^{\circ}\right.$ $\left.35^{\prime} \mathrm{S} 48^{\circ} 45^{\prime} \mathrm{W}\right)$ Paraná, Brazil. SciaenidaeTeleostei. In: SIMPOSIO INTERNACIONAL DE AQUACULTURA. Chile, 1983. p.445-465.

Smith, S. L. 1978. The role of zooplankton in the nitrogen dynamics of a shallow estuary. Estuar. coast. mar. Sci., 7(6):555-565.

Stramma, L.; Fischer, J. \& Reppin, J. 1995. The North Brazil Undercurrent. Deep-Sea Res. I, 42(5):773-795.

Tundisi, J. G.; Tundisi, T. M. \& Kutner, M. B. 1973. Plankton studies in a mangrove environment. VIII. Further investigations on primary production, standing-stock of phyto- and zooplankton and some environmental factors. Int. Revue ges. Hydrobiol., 58(6):925-940.

Tundisi, J. G.; Teixeira, C.; Tundisi, T. M.; Kutner, M. B. \& Kinoshita, L. 1978. Plankton studies in a mangrove environment. IX. Comparative investigations with coastal oligotrophic waters. Rev. Bras. Biol, 38(2):301-320. 
Tundisi, T. M. 1970. On the seasonal occurrence of appendicularians in waters off the coast of São Paulo State. Bolm Inst. oceanogr., S. Paulo, 19:131-144.

Tundisi, T. M. 1972. Aspectos ecológicos do zooplâncton da região lagunar de Cananéia, com especial referência aos Copepoda (Crustacea). Tese de doutorado. Universidade de São Paulo, Instituto de Biociências. 191p.

Turner, J. T. 1984. The feeding ecology of some zooplankters that are important prey items of larval fish. NOAA Tech. Rep., NMFS 7. 37p.

UNESCO. U̇nited Nations Educacional, Scientific and Cultural Organization. 1985. The International System of Units (SI) in oceanography. Paris, IAPSO Publication Scientifique. 32:1-124.
Vervoort, V. 1965. Notes on the biogeography and ecology of marine, free-living Copepoda. In: Van Oye, P. \& Van Micghem, J. eds Biogeography and ecology in Antarctica. Boston, Junk/The Hague, p.381-400.

(Manuscrito recebido 20 novembro 1997; revisado 26 outubro de 1998; aceito 10 dezembro 1998) 